\title{
Hybrid fibre-reinforced geopolymer (HFRG) composites as an emerging material in retrofitting aging and seismically- deficient concrete and masonry structures
}

\author{
Ernesto Guades ${ }^{1, *}$, Henrik Stang ${ }^{1}$, Gregor Fisher ${ }^{1}$ and Jacob Schmidt ${ }^{1}$ \\ ${ }^{1}$ Department of Civil Engineering, Technical University of Denmark, Lyngby, Denmark
}

\begin{abstract}
Fibre-reinforced polymer (FRP) systems have recently become popular in repairing concrete or masonry structures because of their inherent advantages. In spite of these benefits, FRPs have drawbacks having low fire resistance, poor environmental sustainability and incompatibilty with the substrate concrete. The effort to address these issues has led to the development of an emerging strain hardening cementitious (SHC) material using an inorganic polymer known as hybrid fibre-reinforced geopolymer (HFRG) composites. Compared with cement-based SHC composites, HFRG has better bond performance to concrete substrates, higher fire resistance, greater corrosion durability and helps to reduce $\mathrm{CO}_{2}$ emissions. This paper reviews the recent development of HFRG composites as an emerging repair material. Literature reveals that flowability of a fresh HFRG mixture decreases with increasing fibre content though still workable up to $2 \%$ fibre volume. Fibre synergy could result in 10-181\% higher flexural toughness of geopolymer composites than when just using mono fibres. The application of HFRG composites to RC beams increased displacement ductility by to $263 \%$. To date, there has been no reported field application of HFRG as a repair material though mono-fibre FRG has been field-applied as a strengthening material in large-diameter sewer RC pipes, RC culverts, RC sewerage manholes and dam surface improvement.
\end{abstract}

\section{Background}

Many existing buildings and bridges in Europe are in need for rehabilitation to enhance and extend their service performance and life. Retrofitting of these concrete and masonry structures and elements has traditionally used cement mortar patching or steel jacketing, however the use of fibre-reinforced polymer (FRP) systems have recently become popular because of their inherent benefits. FRPs, derived from combining of fibre and organic polymer (i.e. epoxy), are known to perform better than traditional repair systems due to their high specific strength, relative ease and speed of application and high corrosion resistance. The performance of such systems has been thoroughly investigated in the past decades and recently some insitu applications have been reported [1-2]. In spite of these advantages and reasonably successful application, FRP method suffered drawbacks owing to low fire resistance, poor environmental sustainability, incompatibility with the substrate concrete and being relatively expensive [3-4]. The quest to overcome the limitations of FRP systems has led to the development of a relatively new strain hardening cementitious (SHC) material using an inorganic polymer known as fibrereinforced geopolymer (FRG) composite. Instead of using cement as the matrix, FRGs utilize aluminosilicate powder such as fly ash (FA), metakaolin (MK) or ground granulated blast-furnace slag (GGBS) and are synthesized through the process of geopolymerization [5]. Geopolymers are considered to be an environmentally-friendly alternative for cement-based composites since their production does not necessarily emit $\mathrm{CO}_{2}$. In addition, they have good bond strength to the concrete substrates [6], lower creep and shrinkage and greater durability in aggressive environments [7].

The reinforcement in FRG composites can be in the form of short mono-fibres or hybrid fibres. Compared to the first, hybridization offers superior engineering properties because the presence of one fibre enables the more efficient utilization of the potential properties of the other fibre [8]. Consequently, hybrid FRG (HFRG) composites are undoubtedly an ideal strengthening material for structures, especially when situated in aggressive environments. HFRG composite is an emerging strengthening material and is relatively new in this application, therefore an effort is made to gather relevant information from the previous studies. This paper presents the recent information on HFRG from literature sources. The discussion is concentrated on the concept of fibre hybridization and its effect on the fresh and hardened state properties of the geopolymer composites. In addition, laboratory-based findings and field application performance of FRG-strengthened concrete and masonry structures are discussed. It is expected that the knowledge provided in this paper could

*Corresponding author: ergua@byg.dtu.dk 
contribute in the development of effective FRG repair system guidelines and leading to their global acceptance.

\section{HFRG material constituents and fibre hybridization}

Fly ash, MK and GGBS are the most common precursor material in producing geoplymer. FA is an industrial byproduct of burning coal or lignite deriving from electricity generating plants. The particle size, curing time, curing temperature and the alkaline solutions are considered major parameters that affect the mechanical strength of the fly ash-based geopolymer. MK is formed by a controlled calcination process of the clay mineral kaolinite that contains high $\mathrm{SiO}_{2}$ and $\mathrm{Al}_{2} \mathrm{O}_{3}$ [9]. The chemical solutions, curing system and the characteristics of the MK used greatly affect the initial reaction process and performance of the MK-based geopolymer. On the other hand, GGBS is a non-metallic material from heating iron ore, coke and limestone to a temperature between $1500^{\circ} \mathrm{C}$ to $1600^{\circ} \mathrm{C}$ [10]. The ores, fluxing stone and impurities in the coke charged into the blast furnace are the factors affecting the composition and properties of GGBS. Among these binding materials, MK-based geopolymer has been shown to have less impurities, exhibits good mechanical properties and easier control on the $\mathrm{Si} / \mathrm{Al}$ ratio [11]. However, $\mathrm{MK}$ is relatively expensive since this material requires manufacturing through the process of calcination, as compared to FA and GGBS that are abundantly available in landfill sites. In the geopolymerization process, alkaline solutions are required to activate either FA, MK or GGBS. The most common alkaline activator that is suitable for FA, MK or GGBS is a combination of sodium silicate $\left(\mathrm{Na}_{2} \mathrm{SiO}_{3}\right)$ and sodium hydroxide $(\mathrm{NaOH})$.

Short fibre reinforcement used in HFRG composites for structural applications are usually formed and fabricated from steel (ST), polyvinyl alcohol (PVA), polyethylene (PE), polypropylene (PP), carbon, glass and basalt materials. They can be classified as high modulus (i.e., steel and carbon) and as low modulus (i.e., PVA, PE, PP, glass and basalt). The high modulus fibre usually achieve its optimal response at small to medium crack openings while the low modulus fibre would develop its capacity only at large cracking [12]. If hybridized, high and low modulus fibres are anticipated to produce a composite material with excellent crackmitigating performance. In fibre-reinforced concrete, theoretically macro-fibres increase the composite toughness by bridging macro-cracking while microfibres enhance the response to micro-cracking prior to the formation of macro-cracks [13]. If combined, it is expected that micro-fibres will enhance the pull-out capacity of the macro-fibres resulting in composites with high strength and toughness [12].

\section{Workability of fresh HFRG composites}

Figure 1 shows the effect of different hybrid fibre combinations on the workability of fresh geopolymer composites. Attempt to quantify the effect of fibre hybridization on the workability of fresh FRG composites have been done in [14]. This study combined two steel fibres (i.e., spiral + hooked end) and found that, like in a mono fibre reinforcement, increasing its combined fibre content decreased the workability of the mixture. Combining different materials (i.e., steel $+\mathrm{PE}$ ), however, does not necessarily result in the same trend since an optimum flow value can be obtained at a combined fibre volume content of $1.5 \%$. Increasing the amount of PE fibre in (steel + PE) combination at a fixed fibre ratio at $2 \%$ reduced the fluidity of mixes containing them because of its relatively lower density [14-15]. Regarding the effect of the steel/PE fibre ratio at a fixed volume fraction, it can be observed from Figure 1 that decreasing the amount of steel (i.e., increasing the

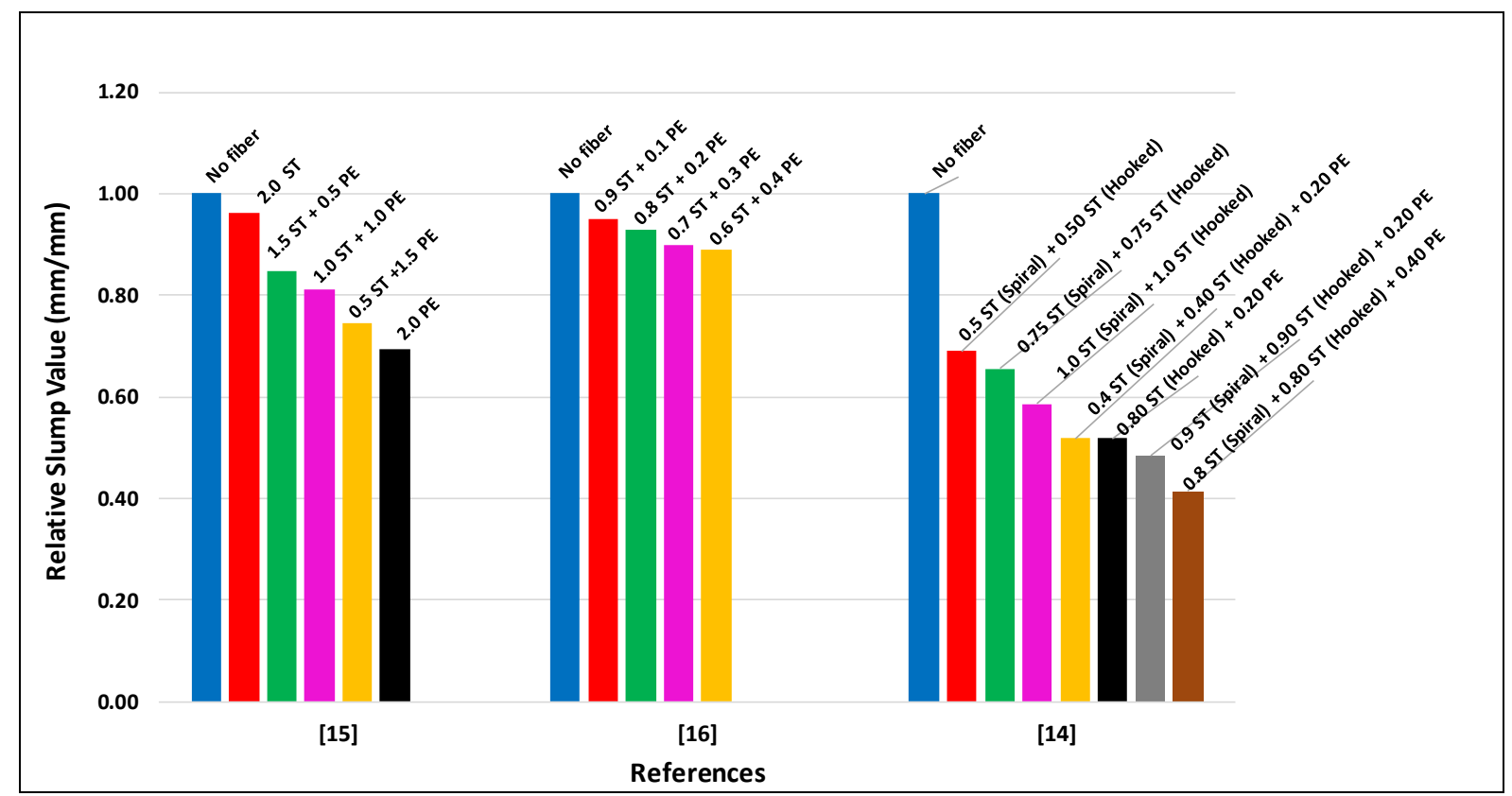

Fig. 1. Workability characteristics of HFRG composites. 
PE fibres) would generally drop the flowability of the HFRG composites. This finding was also observed in [15] and [16] whereby the higher the steel fibre volume used in a fixed (steel + PE) combination, the higher the workability found. Meanwhile, Gao et al. [17] characterized the slump flows of samples with $1 \%$ fibre volume content at different long/short fibre ratios (i.e., $80 / 20,60 / 40,40 / 60$ and 20/80) and reported that higher long/short fibre ratio exhibited a relatively low slump. The information on the effect of fibre hybridization on the flowability of fresh FRG composites is rather limited, and apparently additional studies in this aspect need to be conducted due to its complexity. FA-based FRG composite is observed to be more workable than slag-based composite because of its inherently smooth spherical shape bringing a ball-bearing effect that reduces internal friction in the mixture. Other factors that influenced the workability condition of fresh FRG composites include fibre types and smoothness, fibre mechanical properties, alkaline activator properties, and other admixtures $[7,17]$.

\section{Mechanical properties of HFRG Composites}

Figures 2-5 summarize the different studies utilizing hybrid fibres and the effect of hybridization on the mechanical properties of FRG composites. It should be noted that the hybrid combinations included in the figures (details shown in Tables 1 and 2) are the ones producing the highest strengths or toughness, nevertheless other combinations can be found in the individual concerned studies. Moreover, the values indicated for the studies of [15] in Figure 5 are from the fracture toughness calculation instead of the flexural toughness. It can be observed from Figures 2-3 that compressive and tensile strengths of hybrid composites are typically in between the envelopes of the composites utilizing mono fibres. Hybridization does not play a significant contribution to enhance the strengths of composites under compressive and tensile loadings especially if the synergy is between fibres of different materials (i.e., steel combined with PP, PE or glass fibres). The closest compressive strength variation between the hybrid and mono fibre composites with highest strength is around $2 \%$ with $10 \% \mathrm{PP}+90 \%$ steel combination [16]. On the other hand, the closest difference in tensile strength is $7 \%$ when using synergy of ( $0.5 \mathrm{PP}+1.0$ Steel, $\%$ by volume) fibres compared to 1.5 Steel mono fibre [18]. However, there is a tendency that hybridization becomes significant if the combination is on the length of fibres with same material type. For instance, Gao et al. [17] found out that combining $60 \%$ of long steel fibre and $40 \%$ of short steel fibre (\% by weight in total steel fibre combination) yields an increase in compressive strength of 5-9\% compared when only using long or short steel fibre alone. Accordingly, hybridization presents a synergetic effect by constraining the cracks from both micro and macro intensities, resulting in the occurrence of an optimum compressive strength.

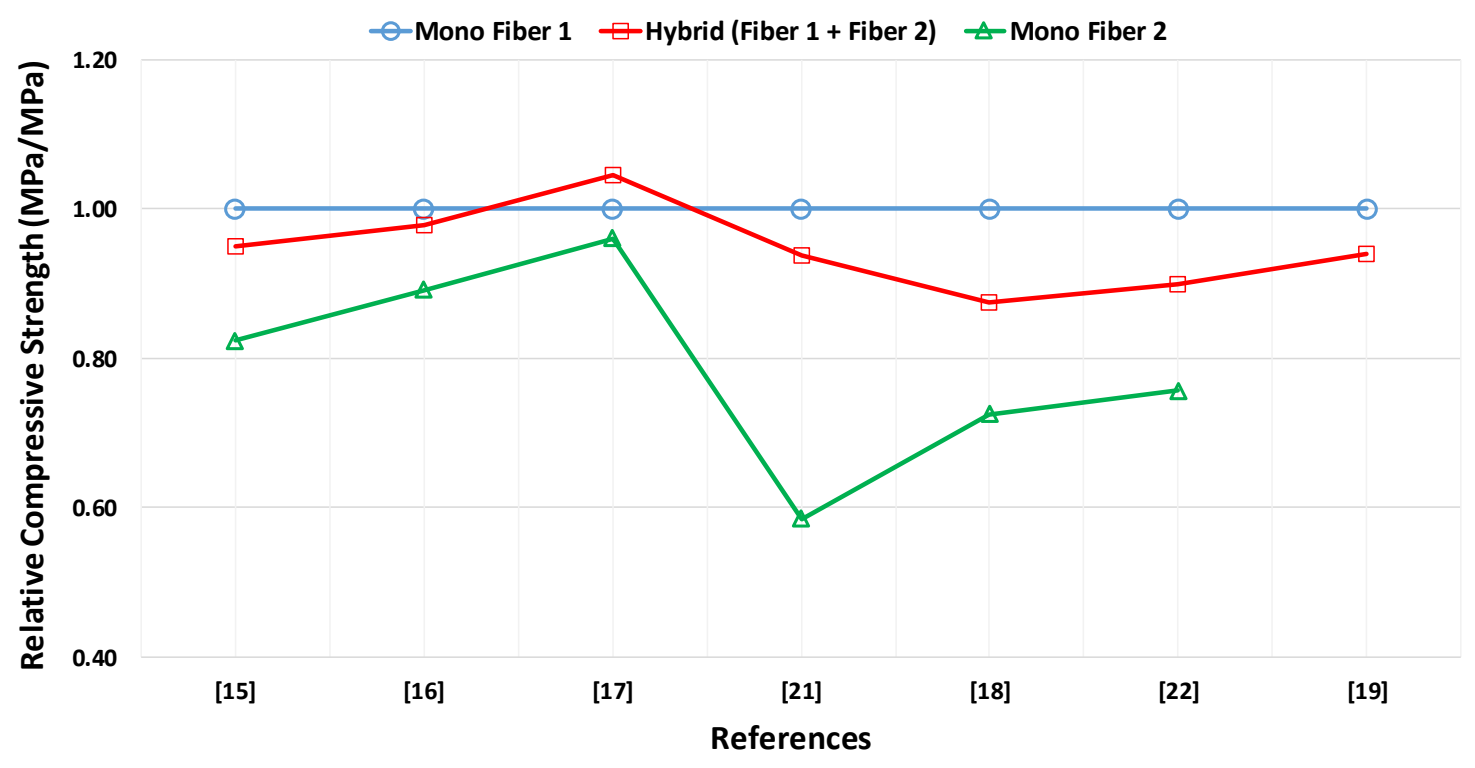

Fig. 2. Relative compressive strength of HFRG composites. 


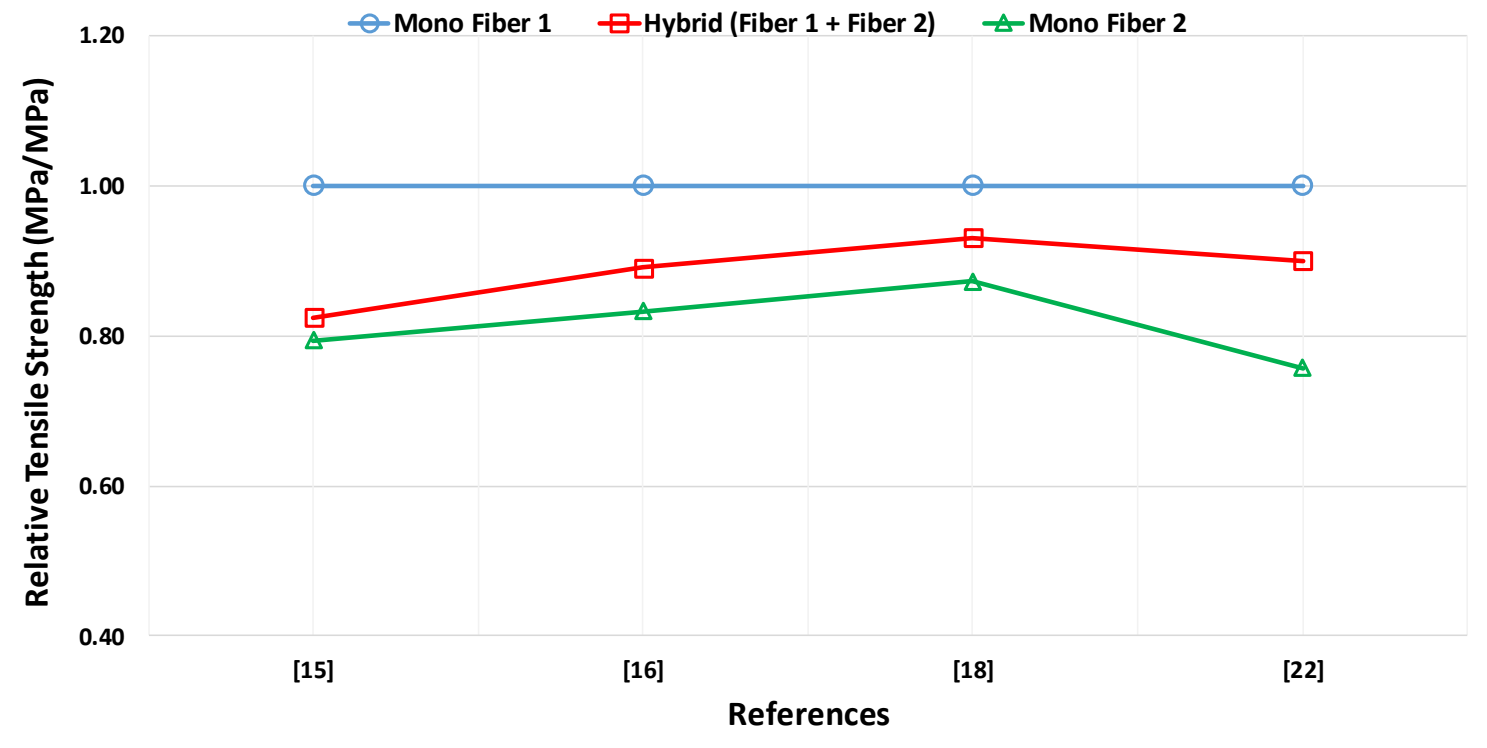

Fig. 3. Relative tensile strength of HFRG composites.

Table 1. Fibre combinations of FRG composites for compressive and tensile properties.

\begin{tabular}{|l|l|l|l|l|}
\hline Mechanical properties & References & ${ }^{\text {a Mono fibre 1 }}$ & ${ }^{\text {a}}$ Hybrid & ${ }^{\text {a Mono fibre 2 }}$ \\
\hline & {$[15]$} & $2.0 \mathrm{ST}$ & $0.5 \mathrm{PE}+1.5 \mathrm{ST}$ & $2.0 \mathrm{PE}$ \\
\hline & {$[16]$} & $1.0 \mathrm{ST}$ & $0.1 \mathrm{PP}+0.9 \mathrm{ST}$ & $1.0 \mathrm{PP}$ \\
\cline { 2 - 5 } Compressive strength & {$[17]$} & $1.0 \mathrm{ST}$ Long & $0.6 \mathrm{ST}$ Long + 0.4 ST Short & $1.0 \mathrm{ST}$ Short \\
\cline { 2 - 5 } & {$[18]$} & $1.5 \mathrm{ST}$ & $0.5 \mathrm{PP}+1.0 \mathrm{ST}$ & $1.5 \mathrm{PP}$ \\
\cline { 2 - 5 } Tensile strength & {$[19]$} & $1.6 \mathrm{ST}$ & $1.3 \mathrm{ST}+0.3 \mathrm{Glass}$ & $1.6 \mathrm{Glass}$ \\
\hline & {$[21]$} & $1.0 \mathrm{ST}$ & $0.2 \mathrm{PP}+0.8 \mathrm{ST}$ & $1.0 \mathrm{PP}$ \\
\hline & {$[22]$} & $3.0 \mathrm{ST}$ Long & $3.0(\mathrm{ST}$ Long + 3ST Short $)$ & $3.0 \mathrm{ST}$ Short \\
\hline & {$[15]$} & $2.0 \mathrm{ST}$ & $1.0 \mathrm{PE}+1.0 \mathrm{ST}$ & $2.0 \mathrm{PE}$ \\
\cline { 2 - 5 } & {$[16]$} & $1.0 \mathrm{ST}$ & $0.1 \mathrm{PP}+0.9 \mathrm{ST}$ & $1.0 \mathrm{PP}$ \\
\cline { 2 - 5 } & {$[18]$} & $1.5 \mathrm{ST}$ & $0.5 \mathrm{PP}+1.0 \mathrm{ST}$ & $1.5 \mathrm{PP}$ \\
\hline & {$[22]$} & $3.0 \mathrm{ST}$ Long & $3.0(\mathrm{ST}$ Long + ST Short $)$ & $3.0 \mathrm{ST}$ Short \\
\hline
\end{tabular}

a\% by volume

The effect of hybridization in the flexural strength of FRG composites (Figure 4) is positive as reported in other studies. Combining 30\% PP and 70\% steel fibres (\% by volume in total PP and steel fibre combination) in composites outperformed $100 \%$ steel mono fibre composites by an $18 \%$ increase in terms of flexural strength performance [16]. Similarly, the blend of $(0.3$ glass +1.3 steel, $\%$ by volume) fibre in the composites brought a flexural strength increase of about $7 \%$ compared to using composites reinforced by steel mono fibre [19]. This increase is mainly attributed to the glass and steel fibre synergy that interconnected the micro and macro cracks in the tensile zone of the composites resulting in effectively controlling crack proliferations. These results indicated that the highest flexural strength can still be achieved by combining two or more materials of different type (i.e., steel + PP of glass) with proper proportioning. One can observe in Figure 4 that hybridization does not really deliver a positive effect to increase the flexural strength when using the same fibre material (i.e., long + short steel fibre combination). Observing Figures 4 and 5, it seems that the effect of fibre hybridization is most substantial in improving the flexural toughness of the FRG composites rather than its strength. Toughness of the composites as repair material is extremely important especially if the structure is under dynamic loadings (e.g., seismic, impact or blast) and therefore hybrid fibres are suitable in these applications. Figure 5 demonstrates that all studies reported an excellent toughening performance provided by HFRG, 
regardless of the method of hybridization. Although the flexural strength of most of the HFRG composites reflected in Figure 4 is intermediately located in the mono fibre system composites, their strain hardening behaviour has been greatly improved. Due to hybridization, high-stiffness or high strength fibres (i.e., steel fibres) maintain their capacity to increase the flexural strength of the composite while low stiffness fibres (i.e., PVA, PP or PE) maintain their ability to increase the deflection capacity of the composite [20], thus increasing their toughness. The maximum increase of the flexural toughness from the mono fibre composites is around $181 \%$ when a combination of $(2.0$ $\mathrm{PE}+0.5 \mathrm{ST}, \%$ by volume) is used. On the other hand, the synergy of $(0.5 \mathrm{PP}+1.0 \mathrm{ST}, \%$ by volume $)$ provided a minimum toughness increase of about $14 \%$. Hybridization using (steel + PVA) yields a better toughening performance than steel $+\mathrm{PP}$ combination because mono PVA fibres are tougher than mono PP fibres. It is worth noting that by properly selecting the ratio, combining long and steel fibres in composites can increase the flexural toughness by almost $100 \%$ compared to using long fibre alone [22].

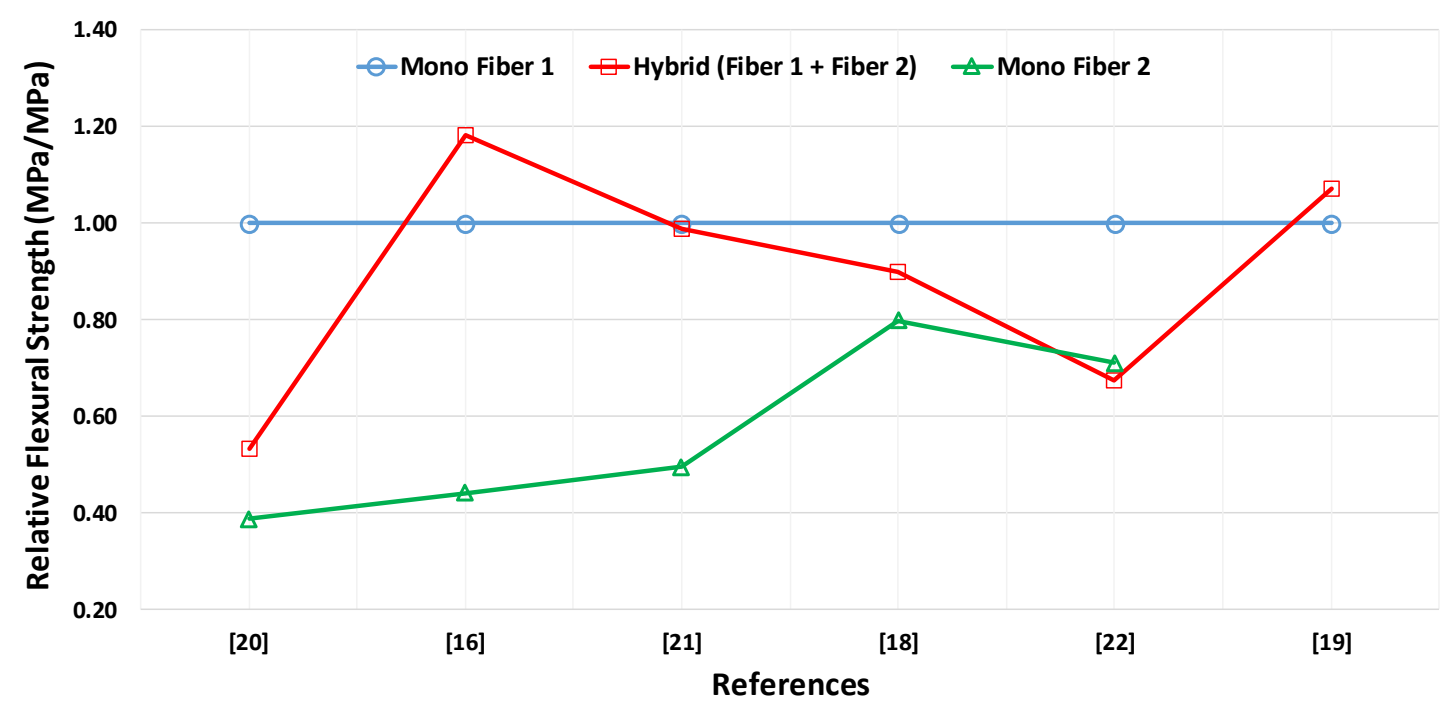

Fig. 4. Relative flexural strength of HFRG composites.

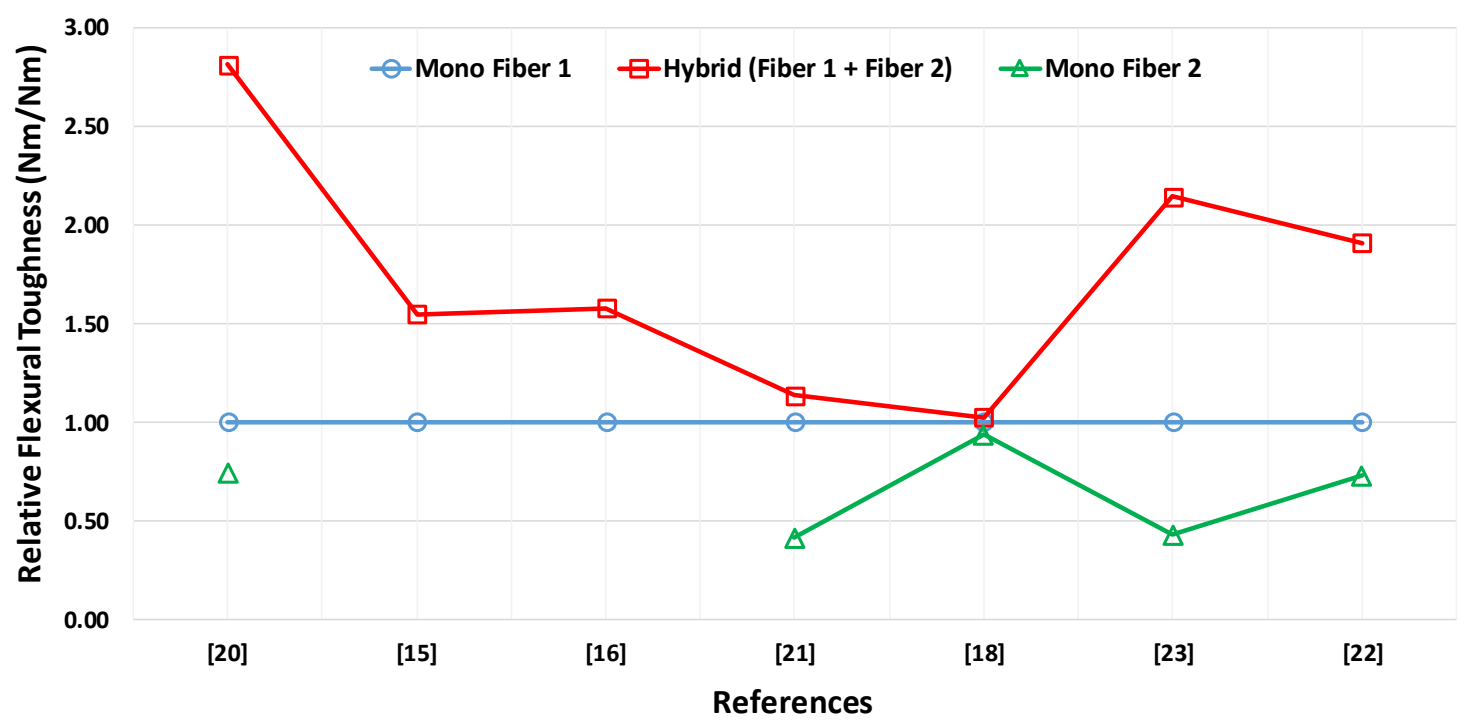

Fig. 5. Relative flexural toughness of HFRG composites. 
Table 2. Fibre combinations of FRG composites for flexural properties.

\begin{tabular}{|c|c|c|c|c|}
\hline Mechanical properties & References & 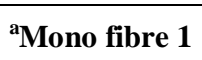 & ${ }^{\text {a}}$ Hybrid & ${ }^{\text {a }}$ Mono fibre 2 \\
\hline \multirow{6}{*}{ Flexural strength } & [16] & $1.0 \mathrm{ST}$ & $0.3 \mathrm{PP}+0.7 \mathrm{ST}$ & $1.0 \mathrm{ST}$ \\
\hline & [18] & $1.5 \mathrm{ST}$ & $0.5 \mathrm{PP}+1.0 \mathrm{ST}$ & $1.5 \mathrm{PP}$ \\
\hline & [19] & $1.6 \mathrm{ST}$ & $1.3 \mathrm{ST}+0.3$ Glass & $1.6 \mathrm{ST}$ \\
\hline & [20] & $2.5 \mathrm{ST}$ & $1.0 \mathrm{PE}+1.5 \mathrm{ST}$ & $2.5 \mathrm{PE}$ \\
\hline & [21] & $1.0 \mathrm{ST}$ & $0.2 \mathrm{PP}+0.8 \mathrm{ST}$ & $1.0 \mathrm{PP}$ \\
\hline & {$[22]$} & 3.0 ST Long & 3.0 (ST Long + ST Short $)$ & 3.0 ST Short \\
\hline \multirow{7}{*}{ Flexural toughness } & [15] & $2.0 \mathrm{ST}$ & $1.5 \mathrm{PE}+0.5 \mathrm{ST}$ & $2.0 \mathrm{ST}$ \\
\hline & [16] & $1.0 \mathrm{ST}$ & $0.3 \mathrm{PP}+0.7 \mathrm{ST}$ & $1.0 \mathrm{ST}$ \\
\hline & [18] & 1.5 PP & $0.5 \mathrm{PP}+1.0 \mathrm{ST}$ & $1.5 \mathrm{ST}$ \\
\hline & {$[20]$} & $2.5 \mathrm{PE}$ & $2.0 \mathrm{PE}+0.5 \mathrm{ST}$ & $2.5 \mathrm{ST}$ \\
\hline & [21] & $1.0 \mathrm{ST}$ & $0.2 \mathrm{PP}+0.8 \mathrm{ST}$ & $1.0 \mathrm{PP}$ \\
\hline & {$[22]$} & 3.0 ST Long & 3.0 (ST Long + ST Short) & 3.0 ST Short \\
\hline & [23] & 2.0 PVA & $1.0 \mathrm{PVA}+1.0 \mathrm{ST}$ & $2.0 \mathrm{ST}$ \\
\hline
\end{tabular}

a\% by volume

\section{Laboratory-based studies on HFRG- strengthened elements}

To date there are limited studies characterizing the behaviour of concrete or masonry elements strengthened with HFRG composites. Krishnaraja and Kandasamy [24] investigated the flexural performance of RC beams strengthened using PVA, PP and steel-based FRG composites. Their study revealed that both mono PVA fibre and ( $\mathrm{PP}+$ steel) fibre combinations improved the initial cracking load response of the repaired concrete by $4.9 \%$ and $7.6 \%$, respectively. However, using (PVA + steel) fibre in combination and mono PP reduced the initial cracking load capacity of the repaired beam by $5.2 \%$ and $8.6 \%$, respectively. When it comes to the ultimate load of strengthened RC beams, they observed a $7-12 \%$ value increase when using either mono or hybrid fibres. Their study also revealed that this strengthening process could provide excellent energy absorption capacity, $71-100 \%$ higher than its un-strengthened counterpart. Among fibres, (PVA + steel) blend offered the highest energy absorption response of around 1,490 $\mathrm{N}-\mathrm{m}$, a result due to a better toughening effect of PVA fibre. The strengthened RC beam exhibited a better ductility performance showing an increase of displacement ductility between 67-263\%, using (PP + steel) fibre combination as the most ductile strengthening fibre material.

There are also reported studies on FRG as repair material, however they focused more on the mono fibre as the reinforcement. For instance, Al-Majidi et al. [25] investigated the performance of a $2.4 \mathrm{~m}$ long $\mathrm{RC}$ beam repaired by $25 \mathrm{~mm}$ and $50 \mathrm{~mm}$ thickness PVA-based FRG composites. They reported that both the initial cracking and ultimate loads of repaired RC beams exhibited relatively higher values than their unrepaired counterparts. This study also showed that the initial cracking load capacity of the strengthened beam without exposing the whole beam to corrosion was substantially enhanced by 41 and $63 \%$ for $25 \mathrm{~mm}$ and $50 \mathrm{~mm}$ thickness repaired layers, respectively. They also stated that the difference between a $25 \mathrm{~mm}$ and $50 \mathrm{~mm}$ repair layer in their initial cracking load values (i.e., 41 and $63 \%$, respectively) is more obvious than in its ultimate load values (i.e., 15 and 14\%, respectively). Majidi et al. emphasized that the typical failure mode of the FRGstrengthened RC beam is flexural fracture and cracks propagating at the mid-span, indicating that a strong and effectively bonded interface was developed between the geopolymer repair material and concrete substrate. Likewise, Sial and Khan [26] studied the flexural response of RC beams with 60 and $90 \mathrm{~mm}$ thickness overlays of PVA-based FRG with or without additional steel reinforcement. Two common findings observed in the studies of [25-26] can be inferred; firstly, different overlay thicknesses apparently improved the initial cracking and ultimate load performances of the repaired beam. Secondly, the effect of increasing layer thickness is only significant in the initial cracking load improvement but not in the ultimate load value. The latter reported an increase in initial cracking load of the fortified RC beam of 63 and $86 \%$ when using 60 and 90 $\mathrm{mm}$ thickness repair overlays, respectively. These values are relatively higher compared to that observed in the study of [24] most probably because the former used thicker repair overlays than the latter. Nevertheless the recorded values in the ultimate load increase of the repaired $\mathrm{RC}$ beams of the two studies are more or less comparable. Donnini and Corinaldesi [27] investigated the behaviour of a concrete column strengthened using a glass or steel fibre reinforced geopolymeric matrix 
system, and compared it with that of an FRP jacketing and fibre-reinforced cement-based matrix (FRCM) system. The result revealed that the FRG repair system enhanced significantly the compressive strength of the concrete column. Using a $30 \mathrm{~mm}$ thickness of glassbased or steel-based FRG could increase the strength to 227 and $289 \%$, respectively. It was found that the FRG system exhibited better compressive strength than an FRP-epoxy wrapping system, the strength of the former was $63-86 \%$ higher than the latter. FRG strengthening method also outperformed FRP-cement mortar wrapping system in terms of compressive strength by $61-69 \%$. However, comparing with the ductility behaviour of the three different systems, this study showed that concrete columns strengthened by FRG composite systems are less ductile than when using FRP and FRCM systems.

\section{Field applications of HFRG composites}

There has been no documented field application of HFRG as a repair material although mono fibrereinforced geopolymer composites have already been used in the rehabilitation of water culverts, pipes and dams. For instance, FRG mortar was spray-applied to repair a fully-deteriorated reinforced concrete pipe (RCP) main sewer in Texas, USA ([28]. The selected test pipe for the demonstration was a $49 \mathrm{~m}$. long, $1.5 \mathrm{~m}$ diameter RCP and was located at a depth of $7.6 \mathrm{~m}$. The FRG mortar that served as lining was a water-activated micro fibre reinforced fly ash-based geopolymer having a compressive, tensile and flexural strength of $55 \mathrm{MPa}$, 5.2 $\mathrm{MPa}$, and 8.3 $\mathrm{MPa}$; respectively. The lining was applied at an approximate thickness of $84 \mathrm{~mm}$ total, which was accordingly well above the design value of 48 $\mathrm{mm}$. The lining process was concluded by smoothing the sprayed surface of the repaired pipe manually using a trowel. Although the repair method using FRG has been successfully demonstrated in deteriorated RCP, Matthews and his associates recommended that a shaker table or a vibrator be used in the future practice to minimize voids and that a need for continuous studies on the finished coating be undertaken.

Similarly, several demonstration projects on the use of FRG in repairing deteriorated culverts and pipe structures have been reported. The rehabilitation projects included large diameter concrete pipes, concrete sewerage manholes, rectangular concrete box culverts and storm water corrugated culvert [29]. The diameter of these concrete pipes ranged between $1.35-1.5 \mathrm{~m}$ and a length of around 53-854 m long. All of these structures were repaired using a spraying-technique of FRG mortar having a thickness in the range of $25-50 \mathrm{~mm}$.

FRG composites were used to rehabilitate a dam that served as a water power plant in Thüringen, Germany [30]. The dam which is primarily made of concrete and dump stone was observed to have cracks on the concrete block wall with spalling and leaky joints. Repair was undertaken in the year 2011 to the dam, having a height of about $17 \mathrm{~m}$ and width of $3.5 \mathrm{~m}$ using a sprayed FRG composite system. The repair mortar contained $2 \%$ by volume of PVA fibre (12 $\mathrm{mm}$ long and a diameter of 40 $\mu \mathrm{m})$ with fly ash as the geopolymer precursor. A total mortar layer thickness of around 30-50 mm and $120 \mathrm{~mm}$ were sprayed on the surface wall and deteriorated joint of the dam, respectively. The final step in the repair process was to manually level the last layer of the sprayed mortar to achieve a smooth surface. No monitoring device was installed in this project, however visual inspection of the retrofitted zone was performed 4 years after its completion. They observed branching and a fine pattern of several cracks above the block joint, nevertheless the FRG-strengthened structure still performed according to expectations. Although the initial performance of the project was satisfactory, Müller and Mechtcherine highlighted that a monitoring system should be installed to collect detailed information of the crack behaviour for further improvement of the system.

\section{Conclusions}

The present study has performed a review on the development of HFRG composites as an emerging material in strengthening concrete structures. Literature reveals as expected that the flowability of fresh HFRG mixtures decreases with increasing fibre content though workable mixes are reported up to $2 \%$ fibre volume. It is known that fibre hybridization in geopolymer composite is more notable in increasing its flexural properties than its compressive or tensile strength. The compressive or tensile strength of geopolymer reinforced by hybrid fibre is between the strength envelopes of the composites with mono fibres. Combining 20\% glass and $80 \%$ steel fibres or $30 \% \mathrm{PP}$ and $70 \%$ steel fibres result in a flexural strength increase of 7-18\%. Fibre synergy could result in a $10-181 \%$ higher flexural toughness of geopolymer composites than when using mono fibres. RC beams strengthened by HFRG exhibited a better ductility performance showing an increase of displacement ductility between 67-263\%, with (PP+ steel) fibre synergy as the most ductile strengthening fibre material. To date, there has been no reported field application of HFRG as a repair material though, mono-fibre FRG has been field-applied as a strengthening material in largediameter sewer RC pipes, RC culverts, RC sewerage manholes and dam surface improvement.

\section{Acknowledgements}

This project has received funding from the European Union's Horizon 2020 Research and Innovation Programme under the Marie Sklodowska-Curie grant agreement No. 713683.

\section{References}

1. J. Strydom, E. du Plessis, L. Pieters, ICCRRR MATEC Web. Conf. 199, 1-9 (2018)

2. E.J. Guades, Recoletos Multidiscip. Res. J. 4:1, 4560 (2017) 
3. F. Bencardino, A. Condello, Constr. Build. Mater. 117, 171-181 (2016)

4. J. Donnini, V. Corinaldesi, ICCRRR MATEC Web. Conf. 199, 1-5 (2018)

5. J. Davidovits, Geopolymer '99 I Conf. (1999)

6. S. Hu, H. Wang, G. Zhang, et al., Cem. Concr. Compos. 30:3, 239-244 (2008)

7. N. Ganesan, R Abraham, S.D. Raj, Constr. Build. Mater. 93, 471-476 (2015)

8. A. Bentur, S. Mindess, Modern Concrete Technology Series: Taylor \& Francis (2009)

9. C. Kuenzel, T.P. Neville, S. Donatello, et al., Appl. Clay. Sci. 83-84, 308-314 (2013)

10. N.I. Ishak, M.A.M. Johari, S.F.S. Hashim, AIP Conf. Proc. 1892, 1-8 (2017)

11. H.Y. Zhang, V. Kodur, S.L. Qi, Constr. Build. Mater. 55, 38-45 (2014)

12. N. Banthia, N. Nandakumar, Cem. Concr. Compos. 25, 3-9 (2003)

13. C.P. Ostertag, J. Blunt, Proc. CBM-CI Intl. Workshop 73-90 (2008)

14. M.Z.N. Khan, Y. Hao, H. Hao, et al., Cem. Concr. Compos. 85, 133-152 (2018)

15. Y. Alrefaei, J.G. Dai, Constr. Build. Mater. 184, 419-431 (2018)

16. C.P. Devika, R.N. Deepthi, Int. J Sci. Res. 4:7, 130135 (2015)

17. X. Gao, Q.L. Yu, R. Yu, et al., Mater. Struct. 50:165, 1-14 (2017)

18. M. Mastali, A. Dalvand, A.R. Sattarifard, et al., Compos. Part B-Eng. 151, 186-200 (2018)

19. N.P. Asrani, G. Murali, K. Parthiban et al, Constr. Build. Mater. 203, 56-68 (2019)

20. F. U. A. Shaikh, M. Maalej, P. Paramasivam, Constr. Build. Mater. 21, 1088-1097 (2007)

21. P. Sukontasukkul, P. Pongsopha, P. Chindaprasirt, et al., Constr. Build. Mater. 161, 37-44 (2018)

22. M.H. Al-Majidi, A. Lampropoulos, A.B. Cundy, Compos Struct. 168, 402-427 (2017)

23. F.U.A. Shaikh, Constr. Build. Mater. 43, 37-49 (2013)

24. A.R. Krishnaraja, S. Kandasamy, Arch. of Civ. Eng. 63:4, 173-189 (2018)

25. M.H. Al-Majidi, A. Lampropoulos, A.B. Cundy, et al., Constr. Build. Mater. 164, 603-619 (2018)

26. S.U. Sial, M. I. Khan, Performance of strain hardening cementitious composite as strengthening and protective overlay in flexural members, ICCRRR MATEC Web. Conf. 199, 1-8 (2018)

27. J. Donnini, V. Corinaldesi, ICCRRR MATEC Web. Conf. 199 (2018) 1-5

28. J. Matthews, A. Selvakumar, S. Vaidya, ASCE Pract. Period. Struct. Des. Constr. 20:4, 1-6 (2015)

29. https://infrastructure.milliken.com (Date accessed: 2 May 2019)
30. S. Müller, V. Mechtcherine, ICCRRR MATEC Web. Conf. 199, 1-6 (2018) 